\title{
Asymptomatic primary biliary cirrhosis
}

\author{
R. A. FOX, P. J. SCHEUER, AND SHEILA SHERLOCK \\ From the Departments of Medicine and Pathology, Royal Free Hospital, London
}

SUMMARY Four asymptomatic patients are described with raised serum alkaline phosphatase values and a positive serum mitochondrial antibody test. In all four needle liver biopsy showed destructive bile duct lesions. Lymphocyte transformation to phytohaemagglutinin was normal in three and impaired in one who also suffered from rheumatoid arthritis. Two patients showed normal skin and serological test responses to dinitrochlorobenzene and haemocyanin.

These four patients are believed to be suffering from asymptomatic primary biliary cirrhosis.

Primary biliary cirrhosis (PBC) is considered an uncommon disease with certain characteristic features. It usually has an insidious onset with pruritus as the first symptom which precedes jaundice by a few days or many years. Anicteric cases of primary biliary cirrhosis are well recognized and about one fifth of the patients may not be jaundiced at the time of diagnosis (Sherlock, 1959). In the original description (Addison and Gull, 1851) the classical features of pruritus, jaundice, xanthelasma, xanthomata, skin pigmentation, and hepatosplenomegaly were present. With the passage of time the diagnosis has been made more readily in less typical and earlier cases before the florid clinical features have developed. This has mainly been due to the widespread application of needle biopsy of the liver and the recognition of early, pathognomonic histological features (Rubin, Schaffner, and Popper, 1965), and more recently the mitochondrial antibody test has proved to be of diagnostic value (Walker, Doniach, Roitt, and Sherlock, 1965). Patients have been investigated and diagnosed even when the clinical presentation has not suggested this as the most likely diagnosis.

Zeegan, Stansfeld, Dawson, and Hunt (1969) reviewed the liver biopsies of 250 patients operated upon for portal hypertension and found that 23 had histological evidence of primary biliary cirrhosis. Only eight of the 23 had been so diagnosed before surgery. The reasons for lack of the correct diagnosis in the remaining 15 is not clear; all were middleaged females and the serum bilirubin and alkaline phosphatase levels were raised in 11. However, from their study it seems clear that some patients can develop portal hypertension, with or without

Received for publication 28 March 1973. a true cirrhosis, without manifesting symptoms of underlying primary biliary cirrhosis in the period before presentation.

Doniach and Walker (1969) have developed a unified concept of 'autoimmune hepatitis' and postulate that primary biliary cirrhosis, active chronic hepatitis, and cryptogenic cirrhosis form a spectrum of disease and are possibly aetiologically related. It is suggested that the overt cases of chronic liver disease represent the 'tip of the iceberg', with many more asymptomatic cases to be discovered in the community. This hypothesis arises from their work with mitochondrial antibody (Walker, Doniach, and Doniach, 1970). These authors screened large numbers of hospital patients for mitochondrial antibody and found 35 positive, and in none was liver disease suspected. On further examination most of these patients did have evidence of subclinical liver disease, and in the eight who were biopsied minor hepatic abnormalities were detected.

Some patients diagnosed as cryptogenic cirrhosis have many features of primary biliary cirrhosis. It therefore seems probable that a diagnosis can be made early in the asymptomatic individuals and furthermore that such patients may reach the stage of cirrhosis before clinical presentation.

Despite the overlap between the various forms of chronic liver disease, primary biliary cirrhosis does have certain typical features which distinguish it. The florid bile duct lesion and its surrounding granuloma is restricted to and is pathognomonic of the first stage (Rubin et al, 1965). This paper describes four asymptomatic subjects who have the histological features of stage 1 primary biliary cirrhosis. Their presentation is described together with the results of some tests of delayed type hypersensitivity. 


\section{Case Histories}

\section{PATIENT 1}

A 43-year-old Jewish housewife presented to her private general practitioner complaining of a stiff, painful neck. A provisional diagnosis of rheumatoid arthritis was made, and blood was sent for antibody studies. During the routine screening mitochondrial antibody was found to be positive to a titre of 1 in 128. The liver function tests were checked and the serum alkaline phosphatase was elevated at $22 \mathrm{KA}$ units per $100 \mathrm{ml}$ (normal 3-13) and the serum cholesterol at $245 \mathrm{mg}$ per $100 \mathrm{ml}$. She was referred for further investigation. No abnormality was found on physical examination. A liver biopsy was performed and showed primary biliary cirrhosis, a destructive bile duct lesion with surrounding granulomatous reaction (see fig).

\section{PATIENT 2}

This 54-year-old housewife was detected during a family study of hyperparathyroidism. Her sister had been diagnosed as suffering from primary hyperparathyroidism and during the study, this patient was found to have an elevated serum alkaline phosphatase of $23 \mathrm{KA}$ units per $100 \mathrm{ml}$, which proved to be of hepatic origin. Her serum cholesterol was elevated at $335 \mathrm{mg}$ per $100 \mathrm{ml}$ and the mitochondrial antibody positive to a titre of 1 in 128. A needle biopsy of the liver revealed stage 1 bile duct lesions and portal tract granulomas.

\section{PATIENT 3}

This 23-year-old housewife attended a gynaecological outpatients department complaining of menorrhagia. No cause was found but on physical examination hepatomegaly was noted. Investigation revealed a serum alkaline phosphatase of $44 \mathrm{KA}$ units per $100 \mathrm{ml}$ and a serum cholesterol of $200 \mathrm{mg}$ per $100 \mathrm{ml}$. The mitochondrial antibody test was positive in a titre of 1 in 256. Liver biopsy revealed stage 1 bile duct lesions and portal tract granulomas.

\section{PATIENT 4}

The fourth patient was a 39-year-old female with incapacitating rheumatoid arthritis. During routine antibody screening the mitochondrial antibody was found to be positive at 1 in 128. Examination showed hepatomegaly and further investigation revealed an elevated serum alkaline phosphatase of $30 \mathrm{KA}$ units per $100 \mathrm{ml}$. Needle biopsy of the liver showed the pathognomonic bile duct lesions of stage 1 primary biliary cirrhosis but there were no granulomas.

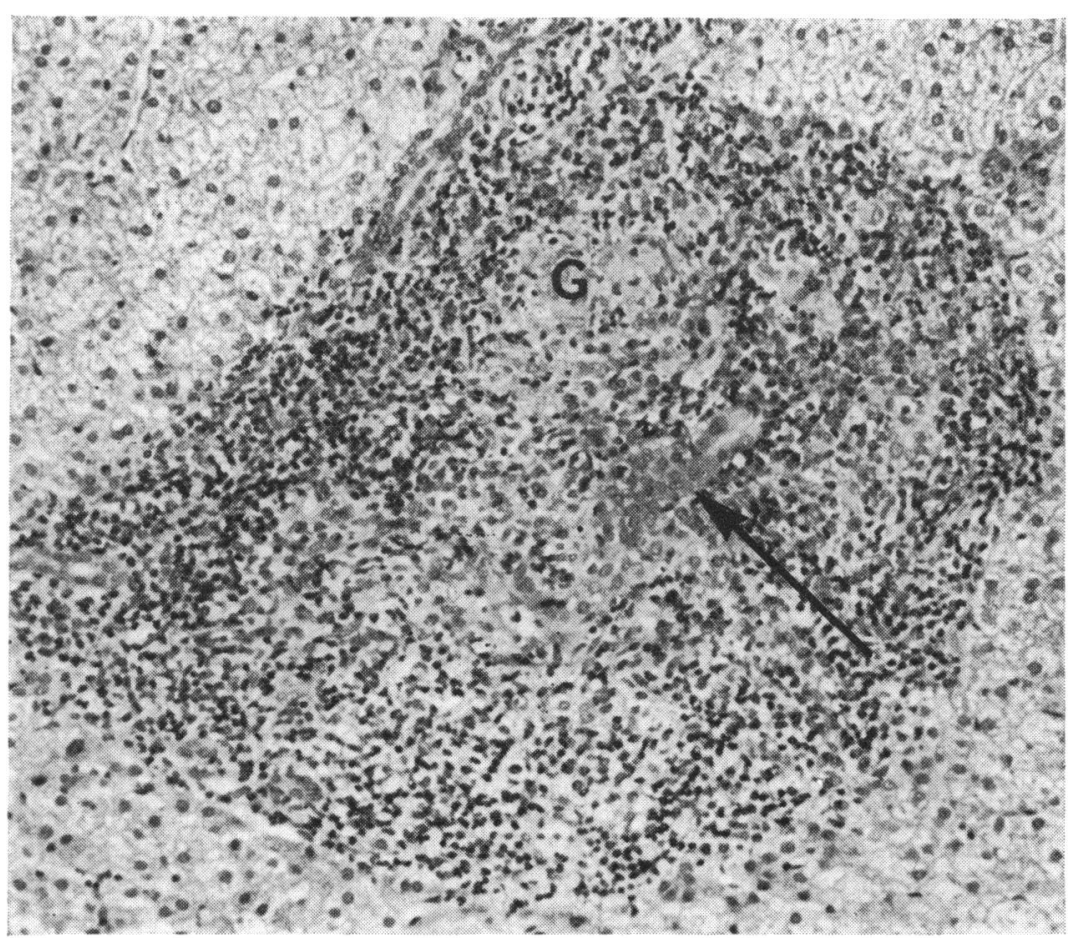

Fig. Patient 1: inflamed and enlarged portal tract from second liver biopsy containing an abnormal bile duct (arrow) and small granuloma (G). Haematoxylin and eosin, $\times 170$. 


\section{Immunological Studies}

The mitochondrial antibody test was positive to a high titre in all four patients. Smooth muscle antibody and antinuclear factor were negative in all. Serum immunoglobulins were measured by radioimmunodiffusion (McKelvey and Fahey, 1965) and the serum IgA was normal in all. Serum IgG was elevated to $1750 \mathrm{mg} / 100 \mathrm{ml}$ in one patient (no. 3) and normal in the rest. Serum IgM has been found to be elevated in about $80 \%$ of patients with primary biliary cirrhosis (Feizi, 1969). It was raised above normal in three of these patients840,550 , and $700 \mathrm{mg}$ per $100 \mathrm{ml}$, and normal in one-140 mg per $100 \mathrm{ml}$ (normal range 37-215 $\mathrm{mg} / 100 \mathrm{ml}$ ).

Normal mechanisms of delayed hypersensitivity have been reported to be impaired in a significant proportion of patients with this disease (Fox, James, Scheuer, Sharma, and Sherlock, 1969). In vitro lymphocyte transformation to phytohaemagglutinin was performed in all patients. It was normal in three and impaired in one. The patient with impaired lymphocyte transformation also had advanced rheumatoid arthritis and was receiving a small dose of prednisone. Two of the patients received further tests of delayed hypersensitivity and both responded normally to dinitrochlorobenzene (Fox et al, 1969) and haemocyanin (Swanson and Schwartz, 1967).

\section{Follow Up}

Two of these patients have been followed for two years. The patient with rheumatoid arthritis still has abnormal liver function tests but there has been no significant change. The second patient described has developed symptoms of cholestasis. One year after the initial visit she developed pruritus. Liver function tests remain abnormal and the liver biopsy still shows stage 1 lesions. This patient received treatment with azathioprine$100 \mathrm{mg}$ daily. The pruritus reappeared when the azathioprine was stopped and disappeared when recommenced.

\section{Discussion}

When the classical clinical features are present, primary biliary cirrhosis can be diagnosed with relative ease. The detection of asymptomatic subjects, although fortuitous, was not unexpected. Once a patient with primary biliary cirrhosis develops symptoms one can predict that she will, after a variable length of time, become jaundiced, although the interval may be as long as 12 years (Fox, 1971).
The usual survival is for six to seven years; the range is from four to 14 years (Sherlock, 1959). The natural history of the disease is quite variable. The duration of detectable disease before symptoms develop is unknown, but this, presumably, is also variable. In only one of the patients would it be justifiable to designate the disease as presymptomatic, in that symptoms did eventually develop. It is possible that the other patients may never develop the clinical syndrome of primary biliary cirrhosis, but further follow up is necessary.

The mitochondrial antibody test has been useful in the detection of these asymptomatic patients as it was in the detection of subclinical liver disease in hospital patients (Walker et al, 1970). This test may well be of value in the detection of early sufferers, but its place may well be confirmatory. Patient 2 was detected by the finding of an elevated serum alkaline phosphatase, and levels of this enzyme were increased in all four patients. With the widespread routine application of the AutoAnalyzer and use of a battery of blood tests on all patients, it is probable that the early, asymptomatic cases might well be detected by finding increased levels of this enzyme.

These early cases showed the positive mitochondrial antibody test and elevated serum levels of IgM found in more advanced forms of the disease. In a previous study on delayed hypersensitivity it was found that about half of the patients with primary biliary cirrhosis had evidence of anergy. This was shown by depression of the tuberculin skin test, by failure of DNCB sensitization, and by reduced lymphocyte transformation in vitro in response to phytohaemagglutinin. There was good correlation between the results of DNCB sensitization and of lymphocyte transformation in vitro and it was concluded that the depression of delayed type hypersensitivity was a result of the disease. Three of the four asymptomatic cases of primary biliary cirrhosis were otherwise clinically normal and the fourth had severe rheumatoid arthritis. Impaired delayed hypersensitivity has been described in rheumatoid arthritis (Whaley, Glen, Dick, Nuki, and Buchanan, 1970) and the only patient here with impaired lymphocyte transformation in response to PHA was the patient with rheumatoid arthritis. With the normal responses in the other three patients it still seems likely that depression of delayed hypersensitivity responses in primary biliary cirrhosis is a result of the disease and not related to aetiology.

The needle biopsy in patients with primary biliary cirrhosis more often gives appearances compatible with the condition rather than diagnostic (Scheuer, 1967). In all the present four cases, 
however, there were pathognomonic bile duct lesions seen in the needle biopsy. In all four there was a surrounding lymphocytic and epithelioid-cell reaction and in three actual granulomas were seen. Such granulomas are known to be more frequent the earlier the disease (Rubin et al, 1965).

The detection of asymptomatic primary biliary cirrhosis confirms previous suspicions but at the same time indicates the problems that are to be faced in understanding the aetiology and pathogenesis of this disease. Patients with primary biliary cirrhosis have a variable natural history. These patients can be detected during the presymptomatic stage, but presumably the length of the stage is very variable. The problems of defining the aetiology of this condition in symptomatic cases when the disease itself may have been present for a long time appear almost insurmountable. If effective therapy is to be instituted in this disease, which inevitably has a fatal outcome, then it should be commenced as early as possible. Detection of asymptomatic cases may therefore be important to allow of early treatment.

\section{References}

Addison, T., and Gull, W. (1851). On a certain affection of the skin, vitiligoidea- $\alpha$, plana, $\beta$, tuberosa. Guy's Hosp. Rep., 7, 265-276.
Doniach, D., and Walker, J. G. (1969). A unified concept of autoimmune hepatitis. Lancet, 1, 813-815

Feizi, T. (1968). Immunoglobulins in chronic liver disease. Gut, 9, 193-198.

Fox, R. A. (1971). An immunological study of primary biliary cirrhosis. MD Thesis, University of Newcastle-upon-Tyne.

Fox, R. A., James, D. G., Scheuer, P. J., Sharma, O., and Sherlock, S. (1969). Impaired delayed hypersensitivity in primary biliary cirrhosis. Lancet, 1, 959-962.

McKelvey, E. M., and Fahey, J. L. (1965). Immunoglobulin changes in disease: quantitation on the basis of heavy polypeptide chains, IgG $(\gamma \mathbf{G})$, IgA $(\gamma \mathbf{A})$, and $\operatorname{IgM}(\gamma \mathbf{M})$, and of light polypeptide chains, type $K$ (I) and type L (II). J. clin. invest, 44, 1778-1787.

Rubin, E., Schaffner, F., and Popper, H. (1965). Primary biliary cirrhosis: chronic non-suppurative destructive cholangitis. Amer. J. Path., 46, 387-407.

Scheuer, P. J. (1967). Primary biliary cirrhosis. Proc. roy. Soc. Med., 60, $1257-1260$.

Sherlock, S. (1959). Primary biliary cirrhosis (chronic intrahepatic obstructive jaundice). Gastroenterology, 37, 574-586.

Swanson, M. A., and Schwartz, R. S. (1967). Immunosuppressive therapy: the relation between clinical response and immunologic competence. New Engl. J. Med., 277, 163-170.

Walker, J. G., Doniach, D., and Doniach, I. (1970). Mitochondrial antibodies and subclinical liver disease. Quart. J. Med., 39, 31-48.

Walker, J. G., Doniach, D., Roitt, I. M., and Sherlock, S. (1965) Serological tests in diagnosis of primary biliary cirrhosis. Lancet, 1, 827-831.

Whaley, K., Glen, A. C. A., Dick, W. C., Nuki, G., and Buchanan, W. W. (1970). Delayed hypersensitivity in Sjøgren's syndrome and rheumatoid arthritis. In Proceedings of the Third Symposium (of the Charles Salt Research Centre): Impaired Cellmediated Hypersensitivity in Man, edited by J. F. Jennings and D. J. Ward, pp. 25-36. Robert Jones and Agnes Hunt Orthopaedic Hospital, Oswestry.

Zeegen, R., Stansfeld, A. G., Dawson, A. M., and Hunt, A. H. (1969) Bleeding oesophageal varices as the presenting feature in primary biliary cirrhosis. Lancet, 2, 9-13. 